\title{
REVIEW ARTICLE OPEN \\ Cranial ultrasound findings in preterm germinal matrix haemorrhage, sequelae and outcome
}

\author{
Alessandro Parodi ${ }^{1}$, Paul Govaert ${ }^{2,3,4}$, Sandra Horsch ${ }^{5}$, Marì Carmen Bravo ${ }^{6}$ and Luca A. Ramenghi ${ }^{1}$ on behalf of the eurUS.brain group
}

Germinal matrix-intraventricular haemorrhage (GMH-IVH), periventricular haemorrhagic infarction (PHI) and its complication, post-haemorrhagic ventricular dilatation (PHVD), are still common neonatal morbidities in preterm infants that are highly associated with adverse neurodevelopmental outcome. Typical cranial ultrasound (CUS) findings of GMH-IVH, PHI and PHVD, their anatomical substrates and underlying mechanisms are discussed in this paper. Furthermore, we propose a detailed descriptive classification of GMH-IVH and PHI that may improve quality of CUS reporting and prediction of outcome in infants suffering from GMH-IVH/PHI.

Pediatric Research (2020) 87:13-24; https://doi.org/10.1038/s41390-020-0780-2

\section{INTRODUCTION}

Epidemiology

Despite improvement in the care of preterm infants, germinal matrix-intraventricular haemorrhage $(\mathrm{GMH}-\mathrm{IVH})$ and parenchymal haemorrhagic infarction $(\mathrm{PHI})$ remain feared complications in this vulnerable population. The overall incidence ranges between 20 and $25 \%$ among very low birth weight (VLBW) infants. ${ }^{1}$ The risk of GMH-IVH increases with decreasing gestational age: ${ }^{2-4}$ in surviving infants born at 24 weeks of gestation, the incidence of the most severe lesions (i.e. grade III GMH-IVH and $\mathrm{PHI}$; the rationale for grading is explained below) ranges between 10 and $25 \%$, while in surviving infants born beyond 28 weeks, such severe injury is diagnosed in $<5 \%$ of cases. ${ }^{2-4}$ GMH-IVH is rarely observed beyond 32 weeks gestation: ${ }^{3}$ in such late-onset cases, it is an epiphenomenon of other diseases like venous thrombosis. ${ }^{5-7}$

\section{Pathogenesis}

The pathogenesis of $\mathrm{GMH}-\mathrm{IVH}$ and $\mathrm{PHI}$ is multifactorial and complex. Gestational age is the most important single independent risk factor. The germinal matrix reaches its maximum volume around 25 weeks gestation and subsequently withers. A residual mass persists until $\sim 36$ weeks gestational age. ${ }^{8-10}$ A venous origin of GMH-IVH has been demonstrated by postmortem studies ${ }^{11,12}$ (Fig. 1). Intrinsic fragility of germinal matrix microvasculature due to immaturity of the vessel wall, fluctuations in cerebral blood flow and the lack of autoregulation seem to represent important contributing factors. ${ }^{13-16}$ Fluctuations in venous pressure, variations in venous anatomy and genetic factors are also part of this complex interplay. ${ }^{17-20}$ Several clinical conditions have been associated with GMH-IVH: perinatal hypoxic-ischaemia, inflammation, cardiovascular instability, severe respiratory disease, pneumothorax, inotropic drug use and many more. ${ }^{21}$ All of them induce fluctuations in $\mathrm{CBF}$, which in turn increase the risk of bleeding from fragile venules. The only single independent factor that has been proven to decrease the risk of GMH-IVH and improve long-term outcome is lung maturation by antenatal glucocorticosteroid treatment. ${ }^{22-24}$ Postnatal indomethacin has been shown to reduce the rate of severe IVH, particularly in male infants, ${ }^{25}$ but did not improve neurodevelopmental or sensory long-term outcome. ${ }^{26}$ Data on the preventive effect of delayed cord clamping are still conflicting, especially when the intrinsic risk of low gestational age is considered. ${ }^{27,28}$

Time of onset

Postnatal GMH-IVH and $\mathrm{PHI}$ occur nearly exclusively during the first week of life. In at least $50 \%$ of affected infants the onset of GMH-IVH is on the first day of life, and by $72 \mathrm{~h}, \sim 90 \%$ of the lesions are identified. Progression to higher grades occurs rapidly, within $1-3$ days..$^{29-33}$ It is striking that premature infants are relatively immune to haemorrhage after the first week of life, irrespective of gestational age. This reduced vulnerability might be related to an increase in blood and tissue oxygen concentration after birth, suppressing vascular endothelial growth factor and angiopoietin-2 levels: a shutdown in angiogenesis after birth would induce maturation of vessels making them resistant to rupture. ${ }^{21,34}$

Foetal intracranial haemorrhage is not uncommon, with an estimated incidence of $0.5-0.9 / 1000$ pregnancies. Antenatal GMH-IVH is the most common type of foetal intracranial haemorrhage. ${ }^{35-37}$ A cranial ultrasound (CUS) on admission allows pre-existing antenatal brain injury to be identified. If antenatal GMHIVH occurred well before birth, residual findings (ventricular dilatation, intraventricular clots and strands, parenchymal defects) may be subtle (see other relevant paper in this issue). PHI with an atypical time of onset (antenatal or after 96 postnatal hours when unrelated to a clinical deterioration) has been associated with the presence of thrombophilic disorders, especially factor $\mathrm{V}$ Leiden. ${ }^{17}$

\footnotetext{
${ }^{1}$ IRCCS, Istituto Giannina Gaslini, DINOGMI Department University of Genoa, Via Gaslini 5, 16148 Genoa, Italy; ${ }^{2}$ Department of Neonatology, Erasmus Medical Center University, Sophia Children's Hospital, Rotterdam, The Netherlands; ${ }^{3}$ Department of Neonatology, ZNA Middelheim, Antwerp, Belgium; ${ }^{4}$ Department of Rehabilitation and Physical Therapy, Gent University Hospital, Gent, Belgium; ${ }^{5}$ Department of Neonatology, Helios Klinikum Berlin Buch, Berlin, Germany and ${ }^{6}$ Department of Neonatology, La Paz University Hospital, Madrid, Spain
}

Correspondence: Luca A. Ramenghi (lucaramenghi@gaslini.org)

Members of eurUS.brain are listed at the end of the paper. 


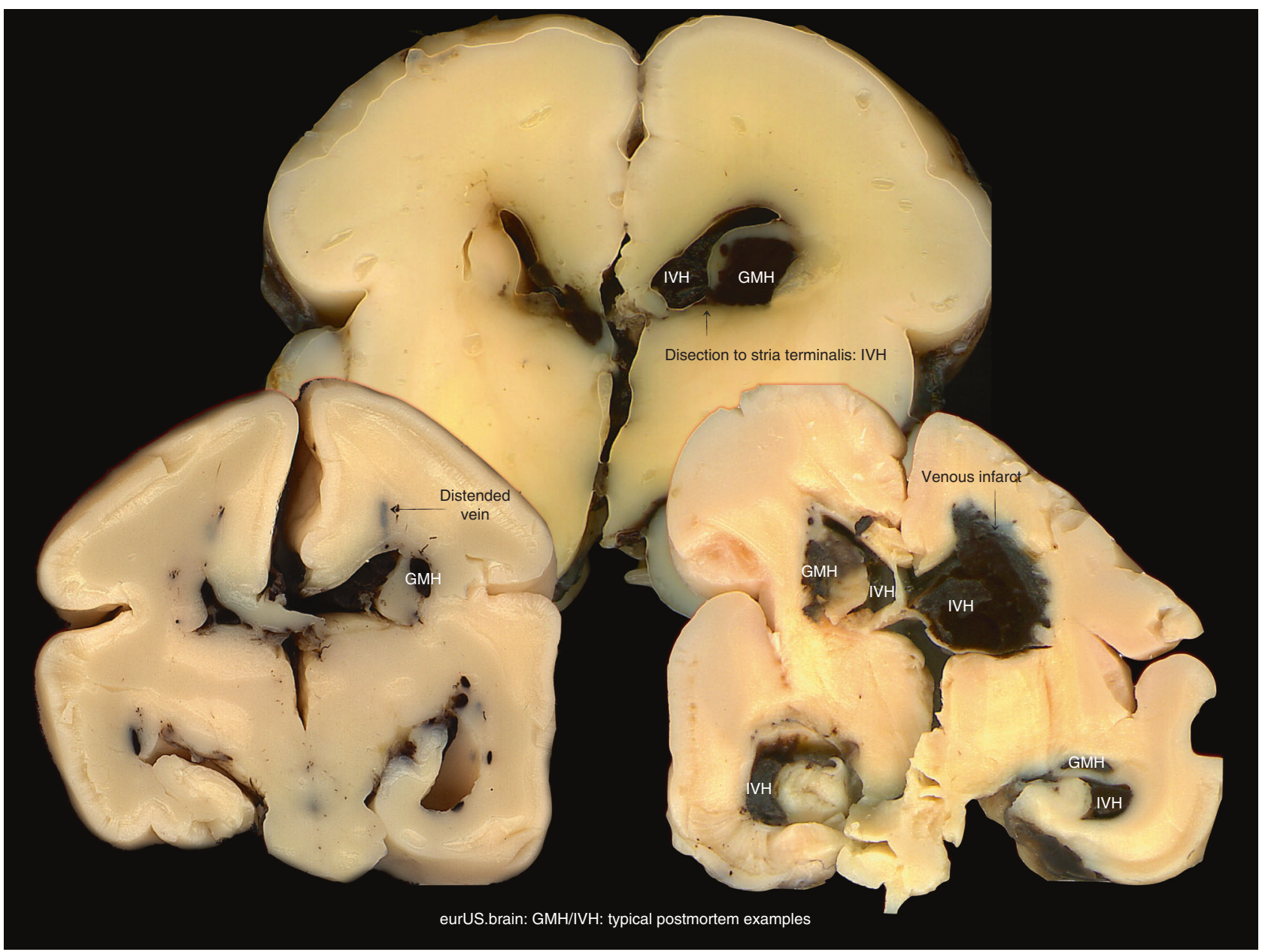

Fig. 1 GMH/IVH: typical postmortem examples.

Clinical presentation in preterm infants

Most instances of GMH-IVH/PHI are clinically silent and detected during routine CUS. Some infants manifest with subtle changes in the level of consciousness, limb movement, tone, and eye movement in the hours to days after the IVH. GMH-IVH and PHI can be accompanied by various degrees of cardiorespiratory instability and anaemia. With extensive haemorrhage, a catastrophic deterioration occurs with stupor, "decerebrate" posturing, generalized tonic seizures and hypotonia.

\section{Outcome of grade I-III GMH-IVH}

Infants with grade III GMH-IVH carry a significantly increased risk of neurodevelopmental disability, especially when GMH-IVH is complicated by post-haemorrhagic ventricular dilatation (PHVD) that needs surgical intervention. Cerebral palsy rates in infants with IVH III range between 7 and $63 \%^{38-40}$ and reflect the heterogeneity of this collective. Infants that suffer low-grade (i.e. grade I or II) GMH-IVH are clearly at much lower risk of developmental disabilities compared to infants with grade III $\mathrm{GMH}-\mathrm{IVH}$ or PHI. Therefore, it has been customary to inform parents that the finding of an uncomplicated low-grade GMH-IVH has no relevant impact on later neurodevelopment and academic achievement. Recent data, though, suggest that this may not be entirely true. ${ }^{40,41}$ It has been shown that low-grade GMH-IVH is followed by microstructural impairment in periventricular and subcortical white matter. ${ }^{42}$ Size, number and location of these minor lesions might be of great importance in infants born at the lowest gestational ages, although robust data are lacking. Matrix injury even after an uncomplicated GMH-IVH results in a relevant loss of glial precursor cells, leading to impaired myelination and cortical development. ${ }^{43,44} \mathrm{GMH}-\mathrm{IVH}$ further triggers inflammation in adjacent white matter through activated microglia, passage of red blood cells and red blood cell degradation: the resulting perilesional tissue injury may be secondary to free radical release and the presence of free iron. ${ }^{45-48}$ The outcome of grade I and II GMH-IVH needs to be prospectively studied in relation to the exact description of size and location in different parts of the matrix protomap of telencephalic development. Similar relevant side effects of intraventricular blood products on the cerebellar external granular layer, after passage into the cerebellar subarachnoid spaces, are not discussed here.

\section{Complications and their outcome}

Parenchymal haemorrhagic infarction. PHI complicates GMH-IVH in $\sim 15 \%$ of cases. ${ }^{49,50} \mathrm{GMH}-\mathrm{IVH}$ of all grades can be complicated by $\mathrm{PHI}$, but the higher the grade of GMH-IVH, the more likely $\mathrm{PHI}$ is to occur. ${ }^{1,51} \mathrm{PHI}$ is caused by venous obstruction induced by GMH-IVH. Venous congestion leads to ischaemia and to secondary haemorrhagic infarction. High intraventricular pressure due to a large haemorrhage may additionally affect flow through the subependymal veins, increasing infarct size. ${ }^{52}$ Cerebral palsy and severe cognitive impairment are common in infants who suffered from PHI. ${ }^{38-40}$ Prognosis is highly dependent on location and extent. ${ }^{53-56}$ Classifying $\mathrm{PHI}$ into venous subtypes helps to predict outcome and counsel parents in this difficult situation, ${ }^{55}$ and this should be expanded in relation to specific behavioural or cognitive sequelae. 
Mortality in infants with extensive $\mathrm{PHI}$ is high, especially when it occurs bilaterally. In many countries, redirection of care and end of life decisions are considered in infants with bilateral PHI. Although robust data on this are lacking, it is certain that redirection of care contributes significantly to reported mortality rates. ${ }^{57,58}$

Post-haemorrhagic ventricular dilatation. The term PHVD refers to dilatation of the ventricles subsequent to GMH-IVH. Approximately $25 \%$ of infants with GMH-IVH develop progressive PHVD. ${ }^{59}$ The risk of PHVD is higher following severe GMH-IVH (i.e. grade III GMH-IVH or PHI)..$^{60}$ The vast majority of instances of progressive PHVD (80\%) follow IVH III, often in combination with a PHI. Most often it follows obstruction of liquor pathways around the cerebellum. While in most cases PHVD eventually resolves ( 40\% spontaneously and another 15\% after nonsurgical treatment), around $35 \%$ of infants with progressive PHVD require surgical treatment, while $10 \%$ die. ${ }^{59}$ Despite decades of extensive research, treatment of PHVD remains challenging. ${ }^{61}$ Several options were investigated: lumbar or ventricular tapping, cerebrospinal fluid (CSF) drainage and fibrinolytic treatment, surgical insertion of an external drain, a subcutaneous reservoir and permanent ventriculo-peritoneal shunting. The key problem is to balance between the adverse effects of PHVD on the immature brain and the risk of complications of interventions (e.g. infection related to CSF tapping, secondary bleeding after fibrinolytic treatment, development of a trapped fourth ventricle). ${ }^{62}$ PHVD is strongly associated with neurodevelopmental impairment, particularly in infants with persistent PHVD that requires surgical intervention and if PHVD is combined with $\mathrm{PHI}^{39}$ However, more recent studies revealed a better outcome than reported earlier. ${ }^{38,63}$ This might partly reflect the heterogeneity of management strategies among centres. A recent multicenter study showed that early treatment of PHVD, based on ventricular measurements, is associated with favourable neurodevelopmental outcomes, even when a permanent shunt is eventually needed. ${ }^{64}$

\section{THE ROLE OF ULTRASOUND IN DIAGNOSING GMH-IVH AND ITS COMPLICATIONS}

Screening for GMH-IVH in the NICU

Preterm infants are often unstable during the first days of life, when GMH-IVH typically presents. CUS allows prompt diagnosis of GMH-IVH as well as assessment of the evolution. ${ }^{65}$ In the most critical phase, CUS should be as "quick and gentle" as possible, in order to minimize stress for fragile neonates. As the incidence of GMH-IVH is closely related to gestational age at birth, ${ }^{66}$ it is reasonable to recommend the following schedule: in preterm infants with a gestational age below 28 weeks or $1000 \mathrm{~g}$, serial CUS should be performed on days 1, 3, 7, 14, 21, 28, and then every other week until term-equivalent age. In stable preterm infants with a gestational age above 28 weeks, the frequency of serial CUS can be limited to days 1, 3, 7, 14,d 28, at 6 weeks and at term-equivalent age. Additional targeted examinations may be warranted in case of clinically or ultrasonographically suspected bleeding with uncertain findings. ${ }^{67}$ CUS examinations beyond the

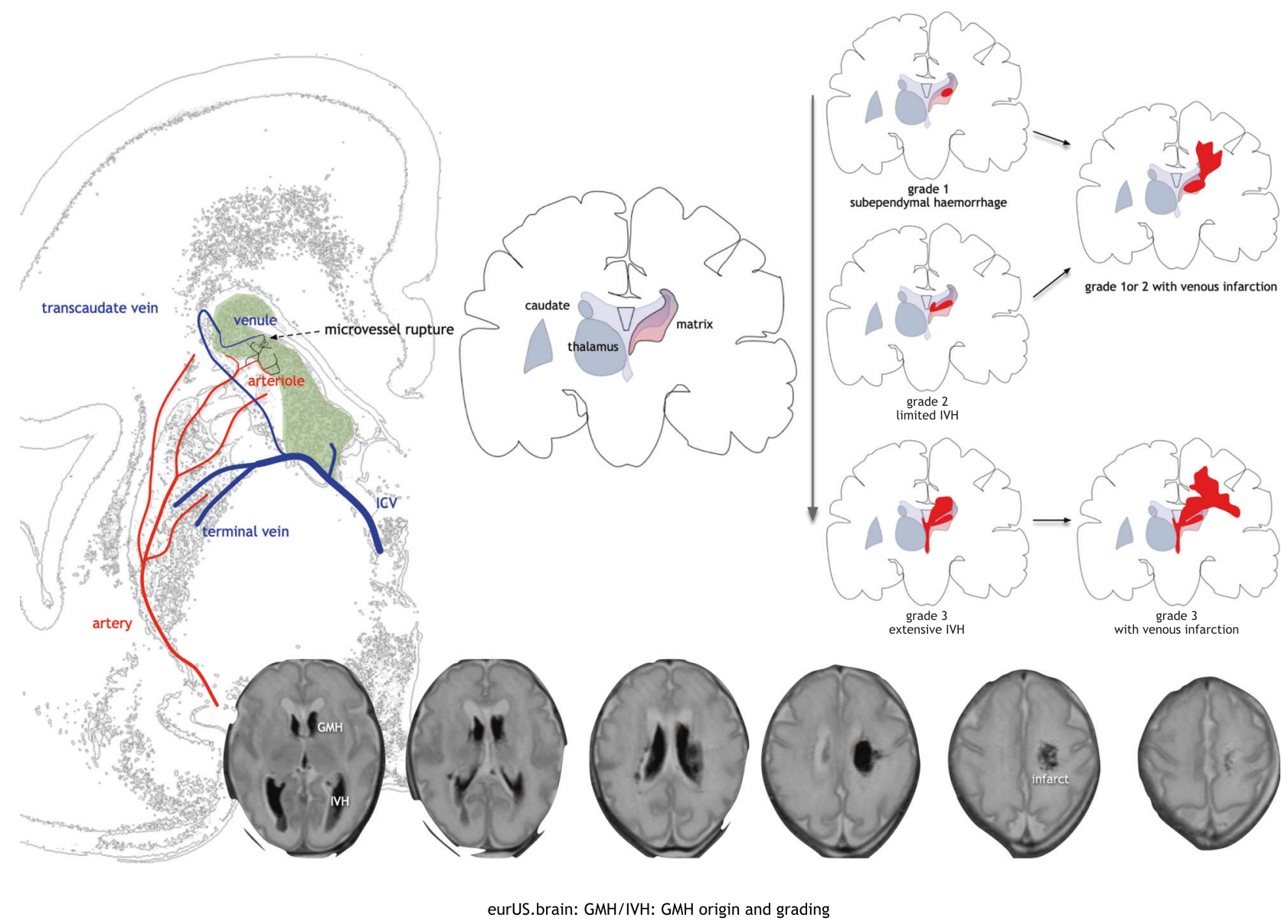

Fig. 2 GMH/IVH: origin and grading. GMH starts in a venule that drains into lateral subependymal collector veins; it extends into white matter by virtue of venous compression and infarction; bottom row: T2-weighted MRI of GMH with limited IVH and limited venous infarct. 
first week of life allow detection of PHVD as well as of uncommon occurrence of late-onset GMH-IVH.

\section{Grading of GMH-IVH}

An early grading system for GMH-IVH was proposed by Papile et al. ${ }^{68}$ in 1978, based on severity assessed by computed tomography. Despite several ultrasound classifications subsequently published, ${ }^{69,70}$ the Papile classification has been widely used for decades by clinicians and researchers. ${ }^{71}$ It suggested that progression from a grade I to a grade IV haemorrhage represents a continuum, as follows: subependymal bleeding limited to germinal matrix (grade I), intraventricular haemorrhage extending into normal sized ventricles and typically filling $<50 \%$ of the ventricular lumen (grade II), intraventricular haemorrhage extending into dilated ventricles (grade III), intraventricular haemorrhage with parenchymal extension (grade IV). However, the formerly called "grade IV" represents periventricular haemorrhagic venous infarction $(\mathrm{PHI})$, rather than parenchymal extension by rupture into the parenchyma of the initial GMH-IVH—although this event very rarely does occur ${ }^{52,72}$ (Fig. 2). As PHI can be associated with any grade of $\mathrm{GMH}-\mathrm{IVH}$, a classification into three grades with separate notation for the presence of PHI, like the Volpe classification, is strongly suggested, both in clinical practice and in research context. ${ }^{1}$ Nevertheless, subependymal GMH and very limited IVH (intraventricular blood $<10 \%$ of the ventricular lumen) were lumped under grade $I$ in Volpe classification, making the

\begin{tabular}{|c|c|c|c|}
\hline GMH & $\mathrm{IVH}$ & Venous inf & arction (PHI) \\
\hline \multicolumn{4}{|l|}{ Size } \\
\hline Largest diameter $<1 \mathrm{~cm}$ & Limited & Medullary & $\begin{array}{l}\text { Entire frontal white } \\
\text { matter up to the atrium }\end{array}$ \\
\hline Largest diameter $\geq 1 \mathrm{~cm}$ & extensive & & $\begin{array}{l}\text { Above caudate } \\
\text { head only }\end{array}$ \\
\hline \multicolumn{4}{|l|}{$\begin{array}{l}\text { Location near caudo- } \\
\text { thalamic groove }\end{array}$} \\
\hline $\begin{array}{l}\text { Above caudate head in front } \\
\text { of the foramen of Monro }\end{array}$ & & & $\begin{array}{l}\text { Thalamostriate } \\
\text { (terminal) vein area } \\
\text { complete (Monro to } \\
\text { atrium) partial }\end{array}$ \\
\hline $\begin{array}{l}\text { Above caudate nucleus } \\
\text { behind the foramen } \\
\text { of Monro }\end{array}$ & & & $\begin{array}{l}\text { Inferior ventricle } \\
\text { vein area }\end{array}$ \\
\hline \multicolumn{4}{|l|}{ Other location } \\
\hline Along temporal horn & & & $\begin{array}{l}\text { Other } \\
\text { Lateral atrial vein } \\
\text { Direct lateral vein }\end{array}$ \\
\hline \multirow[t]{4}{*}{ Other } & & Midline & Septal \\
\hline & & & Callosal \\
\hline & & Striatal & $\begin{array}{l}\text { Superior (thalamostriate } \\
\text { vein territory) }\end{array}$ \\
\hline & & & $\begin{array}{l}\text { Inferior (basal vein } \\
\text { territory) }\end{array}$ \\
\hline
\end{tabular}

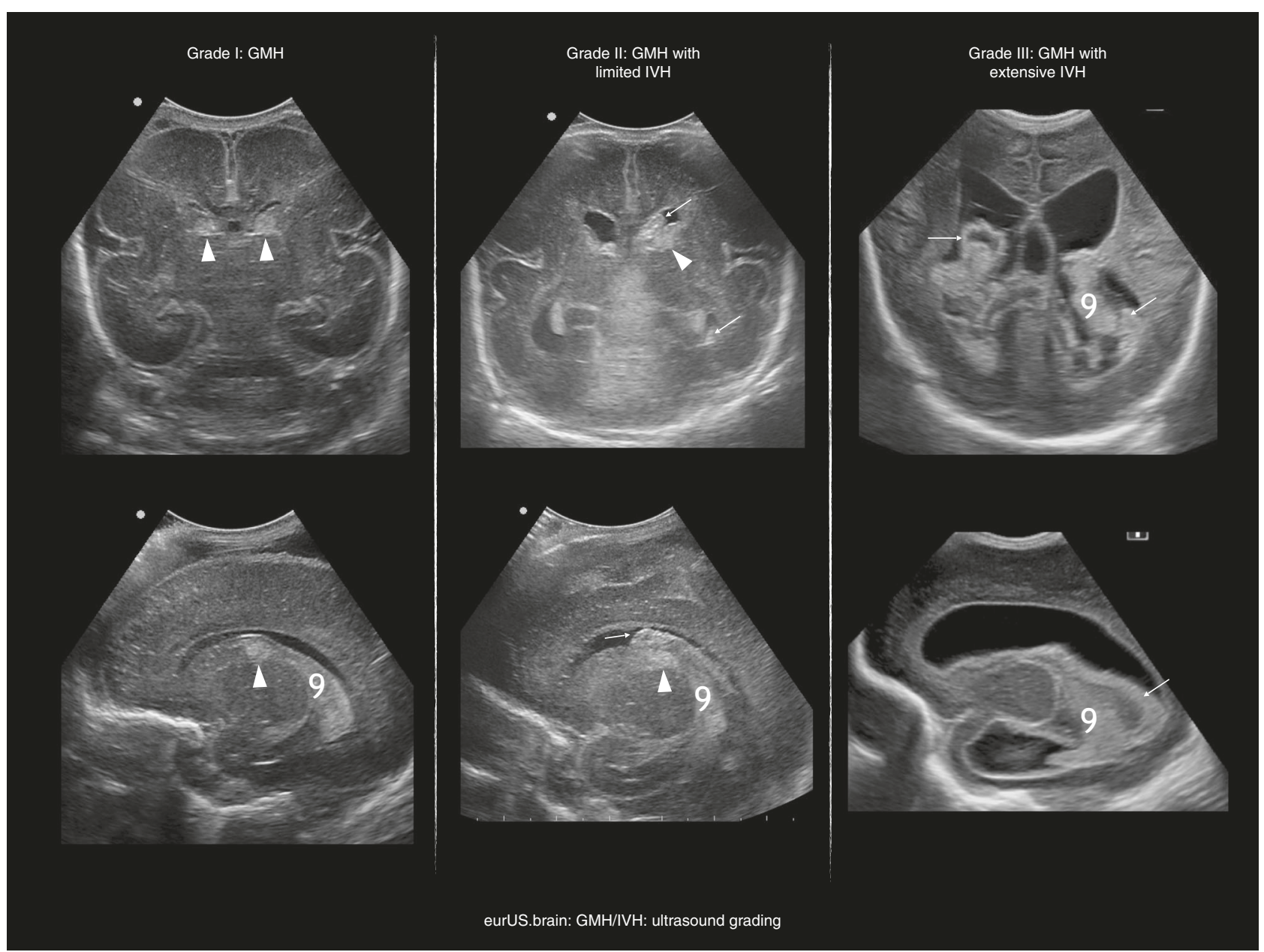

Fig. 3 GMH/IVH: ultrasound grading. CUS grading of GMH/IVH; arrowheads point to $\mathrm{GMH}$, arrows to the presence of clot in the ventricle cavity; asterisk is choroid plexus. 
distinction between these two entities irrelevant. ${ }^{1}$ In light of the above-mentioned studies showing the potential detrimental effects of intraventricular blood on the developing brain, subependymal GMH and limited IVH were separated into two grades in the new classification system we propose in the present paper (Table 1). Furthermore, despite some studies showing that germinal matrix injury results in a relevant loss of glial precursors, the impact of subependymal GMH on neurodevelopment in relation to its extent and location is still unknown: ${ }^{43,44}$ it may therefore become a necessity to further detail descriptions of the extent and location of GMH in the future, although this new classification system needs to be validated in a large cohort of patients before it can be recommended in routine clinical practice.

Ultrasonographic diagnosis of GMH-IVH

When bleeding is limited to the germinal matrix (GMH), the typical CUS finding is a subependymal hyperechoic globular thickening detected during the first week of life, which usually remains visible for a few weeks (Fig. 3). As in some cases, it may be difficult to distinguish a small subependymal GMH from adjacent hyperechoic choroid plexus, both coronal and parasagittal scans should be carefully examined before a diagnosis of GMH is made. ${ }^{69,73,74}$ The most anterior portion of choroid plexus is thin and fills the foramen of Monro at the level of the caudo-thalamic groove; plexus thickens posteriorly, often showing pulsations, is not visible in the frontal and occipital horns of the lateral ventricle and produces a near symmetrical picture in coronal sections. ${ }^{75}$ Asymmetric hyperechoic thickening at the caudo-thalamic groove (the most common location for $\mathrm{GMH}$ ) in coronal planes occurring in the first postnatal days strongly suggests unilateral GMH. Of course, GMH may also occur bilaterally. ${ }^{69,72}$ Conversely, an echogenicity developing at the groove in the late neonatal period should suggest hyperechoic germinolysis rather than late $\mathrm{GMH} .^{76,77}$ Postmortem studies confirmed that the majority of GMHs develop in the caudo-thalamic region, although at postmortem $\mathrm{GMH}$ has been described also in occipital and temporal horns: these regions should be carefully examined during CUS. ${ }^{72,78}$ Neuroimaging studies have demonstrated that diagnostic accuracy of CUS for minor forms of GMH-IVH is suboptimal when compared to the MR-SWI sequence (magnetic resonance-susceptibility weighted imaging), which is considered the most sensitive technique for detection of subtle haemorrhage. ${ }^{79}$

The ependymal layer surrounding the germinal matrix may rupture, allowing extension into the ventricular lumen (IVH), typically at the stria terminalis. IVH can be "limited" or "extensive": in practice "extensive" (grade III according to Papile and Volpe classification) is reserved for haemorrhage that leads to acute ventricle distension by clot and not by CSF, but this remains arbitrary, as measurement of clot volume is not



Fig. 4 GMH/IVH: indirect signs of IVH and unusual extension into cavum vergae. Arrowhead points to GMH; asterisk represents clot in midline cavity. 
possible with ultrasound. The presence of IVH is usually suggested by intraventricular hyperechoic clot located anteriorly to the foramina of Monro, above the caudo-thalamic groove or in the occipital horn. In the latter case, insonation through the posterior or even mastoid fontanelle allows better visualization of the clot. $^{69,75}$ However, identification of a minimal amount of intraventricular blood (i.e. the distinction between "pure" subependymal GMH and a limited IVH) remains challenging. In this context, indirect signs can corroborate a diagnosis of $\mathrm{IVH}^{80}$ hyperechoic ependymal changes appear from 2 to 4 weeks after IVH, while clots from supratentorial origin can be detected in the fourth ventricle and around the cerebellar surface by insonating through the mastoid fontanelle. Ventricular dilatation by large clot (grade III according to Papile and to Volpe classification, or extensive IVH) should be distinguished from PHVD, which takes place after days or weeks due to distal obstruction of CSF circulation and perhaps later to impaired resorption. ${ }^{69}$ Ultrasonographic characteristics of clot changes over time should be always kept in mind in order to consider whether IVH could be of antenatal origin when subacute characteristics of the clot are observed soon after birth, or to suspect an IVH already in its earliest, hyperacute phase. Hyperechogenicity in the acute stage is due to fibrin formation at the end of the clotting cascade and is the main feature of the clot between 4 and $6 \mathrm{~h}$ and 3 days after the bleeding. ${ }^{81}$ In the earliest, hyperacute phase, fresh IVH may remain hypo- or isoechoic, and motion of particulate CSF can sometimes be visible within the ventricles (video particulate CSF with motion). In the subacute phase, after an initial retraction, clot is characterized by progressive hypoechoic change in the central portion and by hyperechoic margins. Intraventricular fibrin strands around the clot can be observed (Fig. 3). In some cases, intraventricular clot fragments remain detectable for months (chronic phase). ${ }^{69,74,75}$ The antenatal origin of an IVH is often suggested by the detection of a subacute clot or clot remnants on the first day of life.

Besides cerebellar haemorrhage, which is often detected in patients with GMH-IVH, an uncommon type of bleeding that can be associated with GMH-IVH is septal haemorrhage. The typical finding is the presence of a clot in the cavum septi pellucidi and/or in the cavum vergae (Fig. 4). Septal haemorrhage may derive from septal veins or from extension of IVH following the rupture of one septal leaflet. ${ }^{82}$ Plexus haemorrhage has been described associated to GMH-IVH in neuropathological studies of VLBW infants. ${ }^{72,83}$ However, discriminating plexus haemorrhage from $\mathrm{GMH}-\mathrm{IVH}$ is difficult for the sonographer in the acute stage.

Ultrasonographic diagnosis of complications of GMH-IVH Periventricular haemorrhagic infarction. Periventricular haemorrhagic infarction (PHI), also referred to as parenchymal haemorrhagic infarction or periventricular venous infarction
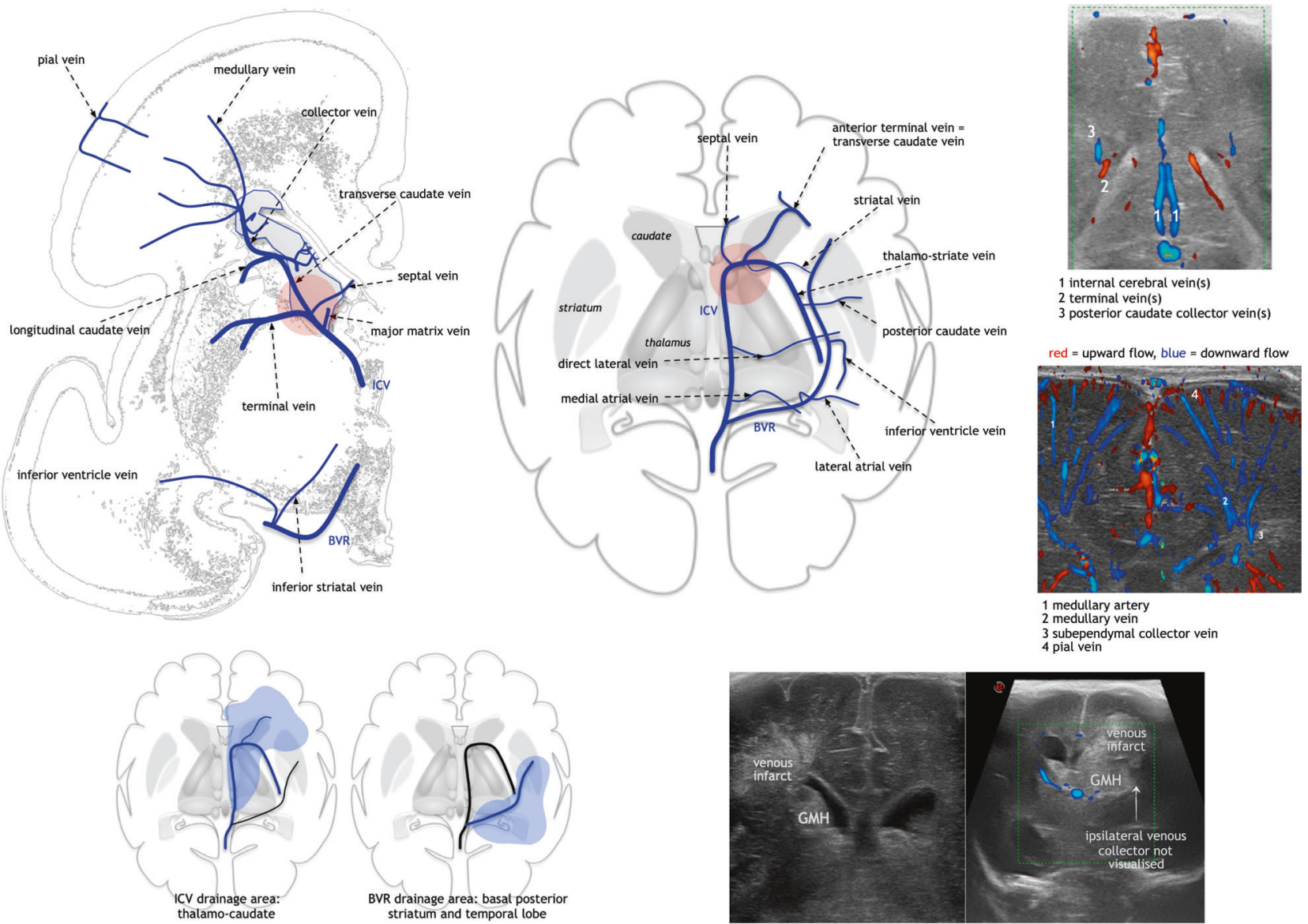

eurUS.brain: GMH/IVH: GMH and deep vein relations

Fig. 5 GMH/IVH: GMH and deep vein relations. Deep venous anatomy and some Doppler examples; in red circles the typical location of GMH near the caudo-thalamic groove; initially the GMH is often separate from a resulting venous infarct; the two may merge, and extensive lesions can be associated with absent terminal vein drainage. 




Extensive terminal vein area infarction with patent terminal vein

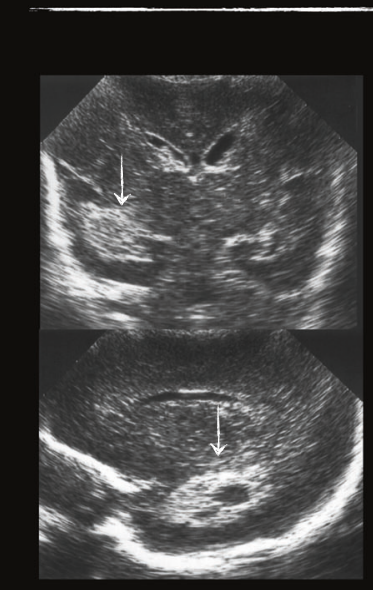

Inferior ventricle vein infarction

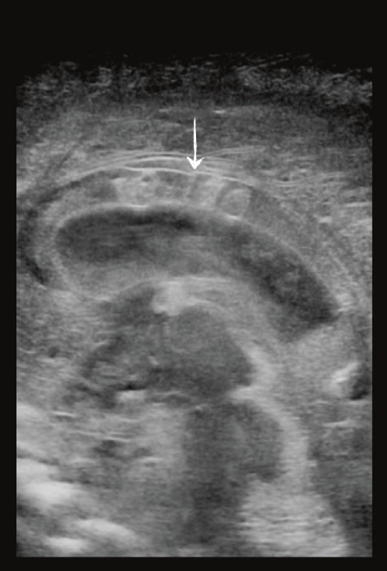

Medial subependymal vein infarction with callosal hemorrhage

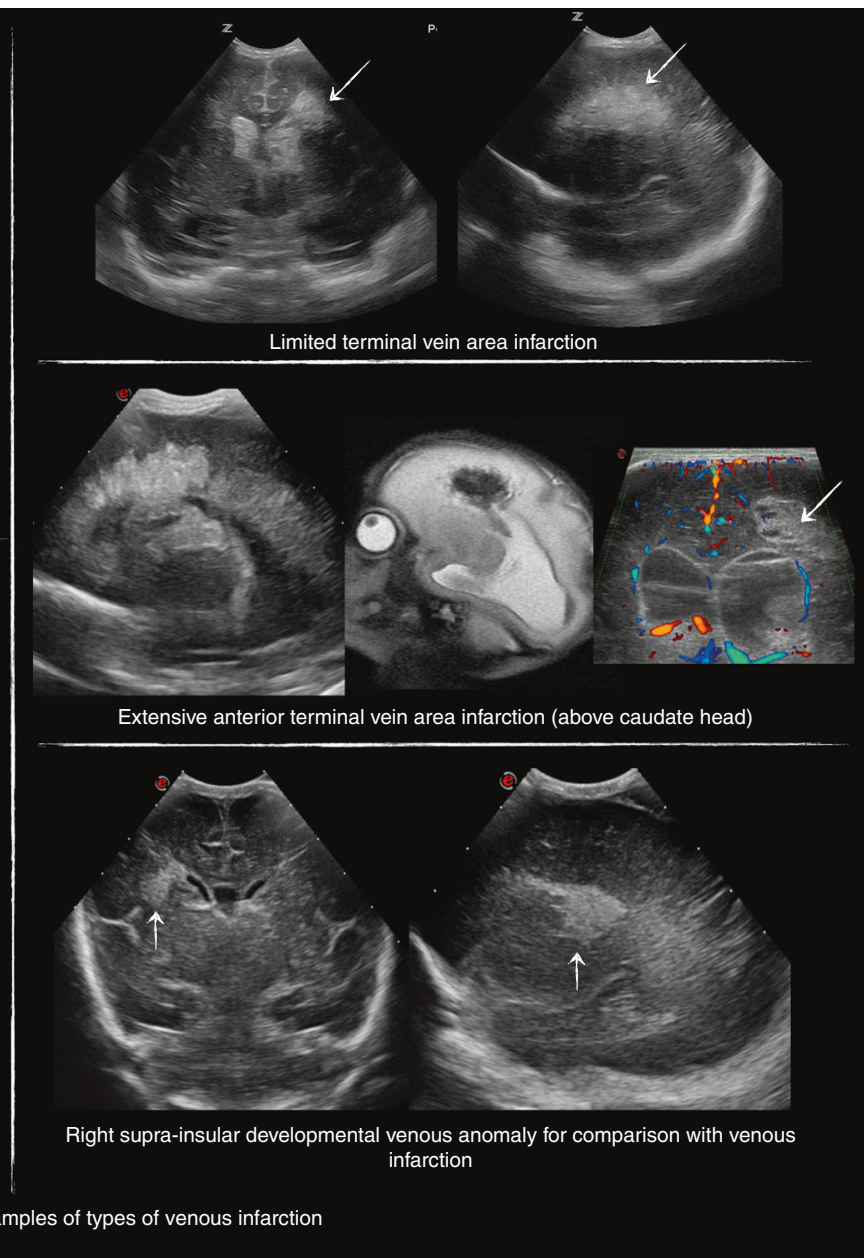

Fig. 6 GMH/IVH: examples of types of venous infarction. Examples of different types of venous infarction: thalamostriate (terminal vein)

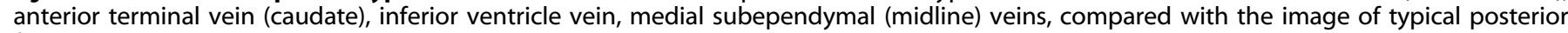
frontal developmental venous anomaly (DVA).

or intraparenchymal lesion, can complicate each grade of GMH-IVH and seems to occur a few hours up to a few days after the initial bleeding. ${ }^{84}$ Postmortem and Doppler studies strongly suggest that this lesion is due to infarction following venous obstruction and congestion. ${ }^{52,85-87}$ It is also likely that arteriolar hypoperfusion secondary to venous obstruction contributes to parenchymal injury (ref.; ${ }^{88}$ Fig. 5).

The characteristic ultrasonographic appearance of $\mathrm{PHI}$ is a triangular, "fan-shaped" echodensity in periventricular white matter, ipsilateral to GMH-IVH ${ }^{51,52}$ (Fig. 6). In the earliest phase, the lesion appears unattached to the ventricle wall; it may subsequently grow, touch the ventricle wall and eventually merge into a single, large hyperechoic lesion together with the initial GMH-IVH. The parenchymal hyperechoic area tends to decrease after few days: this is believed to reflect the resolution of venous congestion in the area surrounding the infarction, which may lead the sonographer to overestimate the extent of $\mathrm{PHI}$ during the acute phase. ${ }^{75} \mathrm{PHI}$ often remains separate from the initial $\mathrm{GMH}$, appearing as a small hyperechoic lesion in ipsilateral periventricular white matter. Multiple minute PHIs along the course of the medullary veins can also be observed. We speculate that such minor PHIs may result from partial obstruction but not occlusion due to compression of a subependymal collector vein by the GMH. The risk of developing $\mathrm{PHI}$ following a subependymal GMH might be related to the location of the GMH itself, especially in association with a peculiar venous anatomy prone to congestion, for example, the presence of acute venous angles.

$\mathrm{PHI}$ usually evolves into cavitation within periventricular white matter. As most PHIs develop adjacent to the ventricular wall, porencephaly resulting from the cavitation is common after 1 or 2 months ${ }^{89-91}$ (Fig. 7). Regardless of the evolution into porencephaly, a cavitation resulting from $\mathrm{PHI}$ is usually single, asymmetric and persistent. Conversely, cysts of periventricular leukomalacia typically show a symmetrical, mainly posterior distribution and tend to disappear within few weeks, insomuch that they are often undetectable at term-equivalent age. ${ }^{1,92}$

Size and location of PHI depend on which vein is obstructed. In some cases, more veins are involved, leading to extensive unilateral or rarely bilateral $\mathrm{PHI} .{ }^{54,55}$ Because a diagnosis of $\mathrm{PHI}$ carries prognostic implications and may raise ethical issues in severe cases, ${ }^{53,58}$ we propose that classification of $\mathrm{PHI}$ should be adopted in routine clinical practice. Dudink et al. ${ }^{55}$ classified PHI into venous subtypes and showed how their classification correlates with motor outcome. Advanced MRI techniques like DTI (diffusion tensor imaging) add useful information for prediction of outcome. ${ }^{93}$ Nevertheless, access to MRI is difficult in low-income countries, limited by obvious logistic obstacles in the acute or early subacute phase of $\mathrm{PHI}$ due to clinical 


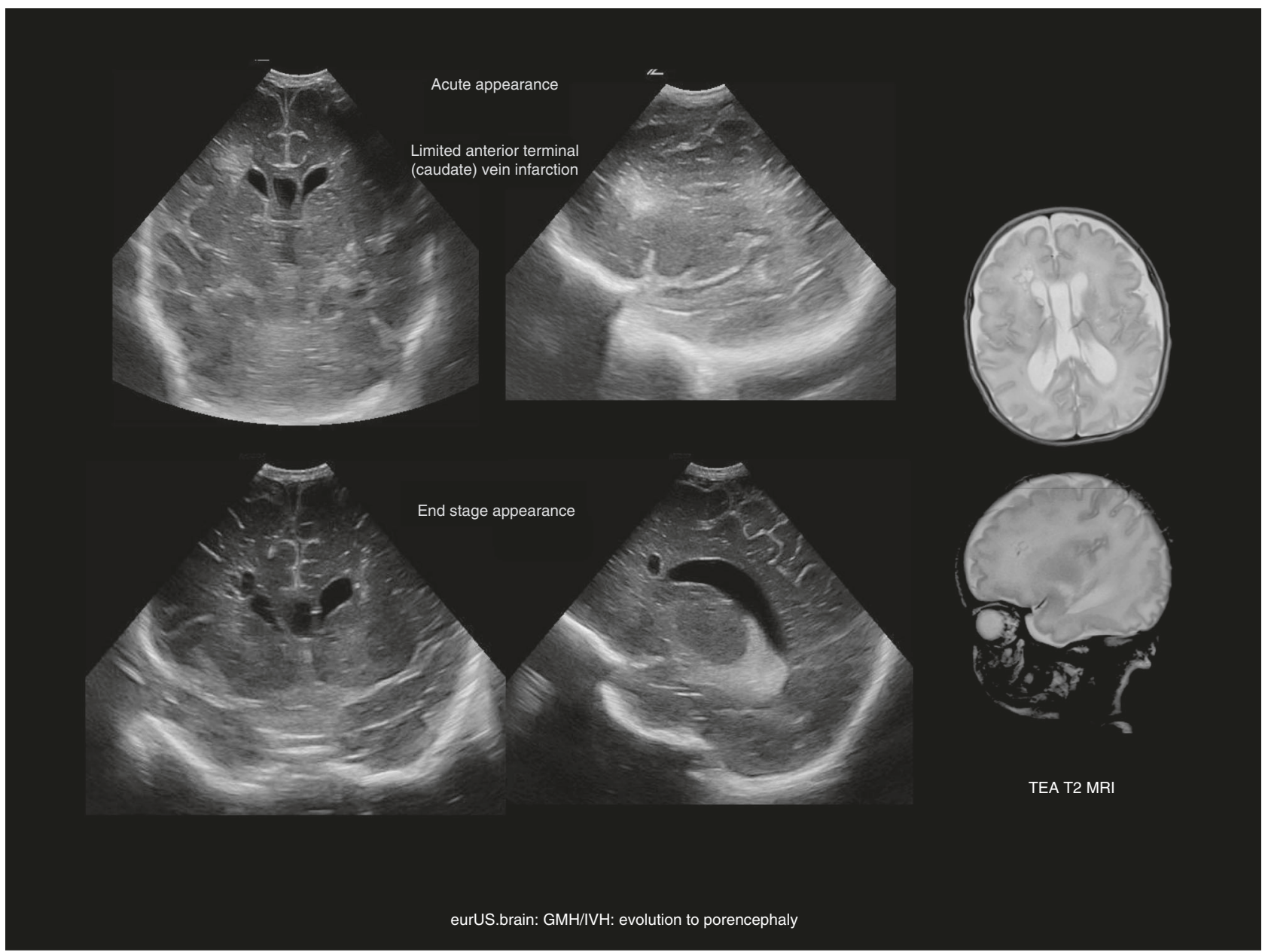

Fig. 7 GMH/IVH: evolution to porencephaly.

instability of the infant. In this context, recognizing the venous subtype of $\mathrm{PHI}$ rather than labelling the lesion as an unspecified "PHI" (or "grade 4") can help the clinician to predict neurological outcome, allowing the start of a targeted rehabilitation programme at an early stage, and may enrich the quality of counselling (see Table 1, Figs. 7 and 8).

Post-haemorrhagic ventricular dilatation. PHVD is caused by an imbalance between production and circulation and/or resorption of CSF. It usually develops a few days to a few weeks after the initial IVH, although exceptionally rare cases developing after term-equivalent age have been reported. ${ }^{94,95}$ Although PHVD is more frequently observed after grade III GMH-IVH and $\mathrm{PHI}$, it may complicate each grade (provided that bleeding has extended into the ventricular lumen). ${ }^{59}$ For this reason, serial ultrasound scans are warranted following GMH-IVH at least until term-equivalent age (Fig. 8). Obstruction to CSF circulation at various levels by clots or by fibrin debris initially contribute to ventricular enlargement. The patient can develop various types of ventricular dilatation according to the location of the obstruction(s): unilateral PHVD following unilateral obstruction at the foramen of Monro, supratentorial (triventricular) PHVD following aqueduct obstruction, complete internal (tetraventricular) hydrocephalus following obstruction of the fourth ventricle outlets (foramina of Luschka and Magendi), combined internal and external hydrocephalus (also referred to as communicating hydrocephalus) following impairment of CSF reasorption in the peritentorial arachnoid spaces. In some cases, the fourth ventricle is isolated from CSF circulation by combined obstruction of aqueduct and the fourth ventricle outlets. ${ }^{59,95,96}$ One relevant advantage of CUS is the possibility to perform repeated scans in order to timely detect PHVD and to follow its evolution before and after treatment. Initial dilatation is often transient with a stable phase followed by regression of dilatation within days or a few weeks. ${ }^{59,97}$ Progression of PHVD can be described with simple serial measurement of the lateral ventricles. Percentile graphs for ventricular size have been published decades ago and were recently reviewed. ${ }^{98-100}$ Ventricular Index (VI) and anterior horn width (AHW), both obtained on a coronal plane passing through the foramina of Monro, are commonly used parameters. However, the absence of significant widening of the frontal horns may sometimes lead to under-estimation of PHVD severity, as neonates tend toward colpocephaly. ${ }^{101}$ Thalamo-occipital distance (TOD) is measured on the parasagittal plane and reflects the degree of dilatation of the trigone and the occipital horn of each lateral ventricle. Reproducibility of these ventricular measurements (VI, AHW and TOD) was at least good in two ultrasound studies assessing both intra- and inter-observer reliability. ${ }^{99,100} \mathrm{VI}$ and AHW are used in most European NICUs to define the threshold for PHVD treatment: although no international consensus exists on optimal timing, the majority of European Centres initiate 




Fig. 8 GMH/IVH: post-haemorrhagic ventricular dilatation. Measurements and inspection of dilated ventricles following extensive IVH ( ${ }^{*}$ third ventricle with extended protrusions).

treatment once the ventricular width has crossed the 97th percentile $+4 \mathrm{~mm}$ line on Levene's graph. ${ }^{102}$ Common findings in severe PHVD include a rounded upper border of the frontal horns on coronal planes (also referred to as "ballooning") and a rounded anterior profile of the third ventricle in the midsagittal plane, due to the markedly dilated infundibular and supraoptic recess. Moreover, a dilated fourth ventricle can be identified in the midsagittal plane in case of tetraventricular or even communicating hydrocephalus. Besides these basics, the routine use of additional acoustic windows can provide useful information to understand the type of PHVD the patient has developed: insonation above the ear, can show a markedly dilated aqueduct in tetraventricular or communicating hydrocephalus, as well as an obstructed aqueduct in triventricular hydrocephalus. ${ }^{75}$ By gently tilting and rotating the probe on a pseudo-axial plane, the sonographer should aim to depict, in the same image, third and fourth ventricle connected by the aqueduct (Fig. 8).

\section{Doppler findings and GMH-IVH}

Although observations were made decades ago about visualization of deep veins in relation to $\mathrm{GMH}$, this is an area where more research is needed. There are not enough Doppler findings published about flow changes near GMH-IVH. Improvement of the Doppler resolution does provide the opportunity to study the terminal vein and its tributaries ${ }^{103,104}$ (Fig. 9). Besides quality of technique (very different between vendors) an important pitfall in interpretation of Doppler observations is the high percentage of variation in deep vein anatomy. The septal and internal cerebral veins are near constantly present in viable preterm infants, but all other veins are not. ${ }^{105}$ Atrial veins and the direct lateral vein can be observed and their anatomy related to the presence of ipsilateral GMH. Variations in deep venous anatomy may either protect against infarction or on the contrary predispose to it; the extent of pial collateralisation may determine infarct size. Future studies may also focus on prevention of venous infarction when a large GMH is observed on admission.

Ultrafast Doppler, a recently developed ultrasound technique, allowed the introduction of functional CUS in animal models as well as in human neonates. Functional CUS detects changes in regional cerebral blood flow triggered by specific patterns of sensory stimulation, by different stages of sleep and by seizures. It has been estimated that this promising technique will be available for the introduction in the clinical setting within a few years. ${ }^{106}$

\section{CONCLUSION}

State of the art ultrasound devices with high-frequency transducers allow today very detailed diagnosis of GMH-IVH/ 


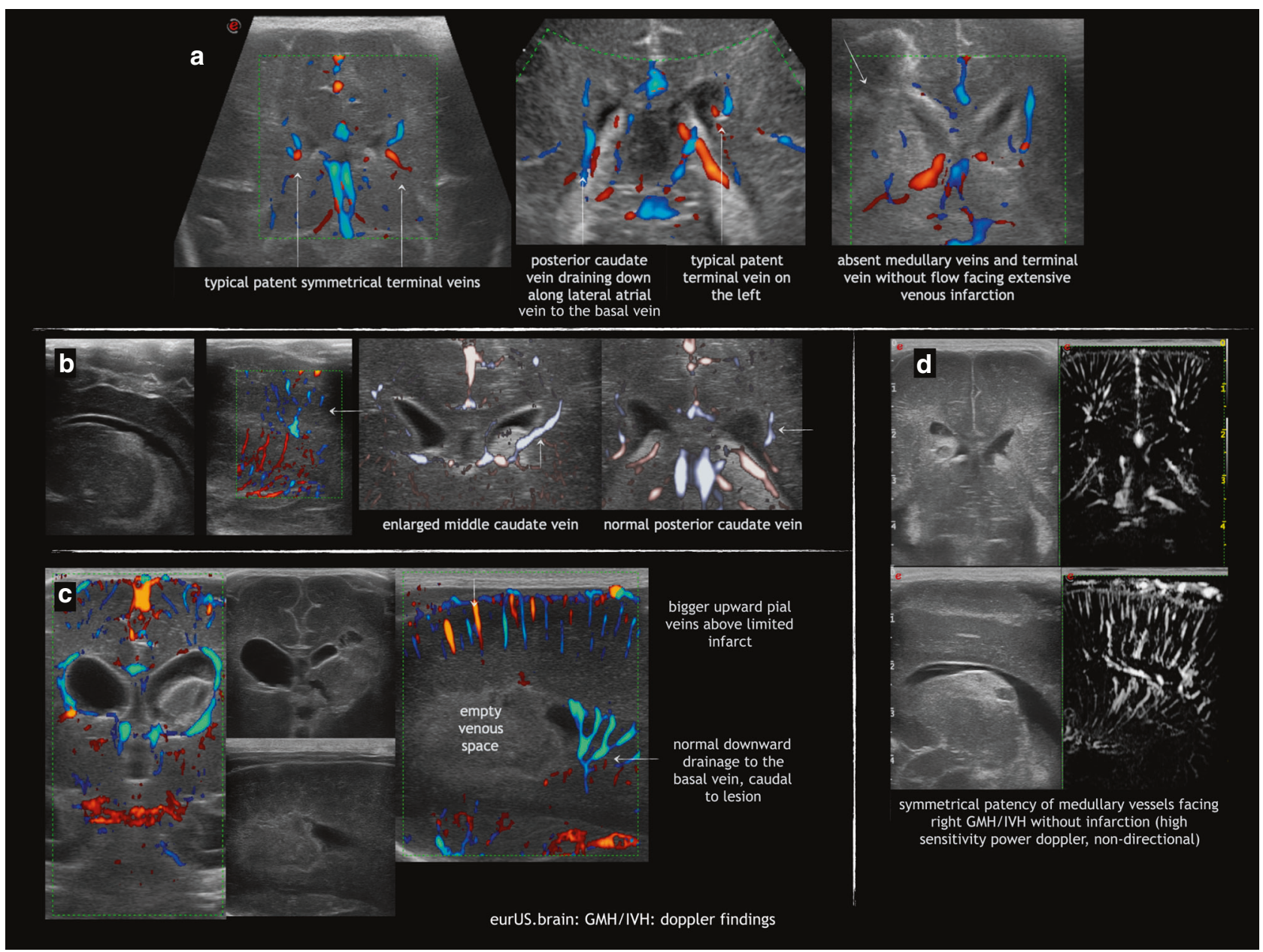

Fig. 9 GMH/IVH: Doppler findings. a Asymmetry in terminal vein size, inversely related to size of ipsilateral direct lateral vein or lateral atrial vein; to be compared with absent terminal vein facing extensive venous infarction. b Apparent enlargement (congestion) of a vein by GMH. c Escape of blood from deep venous infarct along enlarged pial veins, above a Doppler-empty venous space. $\mathbf{d}$ Normal deep venous anatomy in GMH without infarction.

PHI with exact anatomical description of localization and extent of the lesion beyond the up to date commonly used grading systems. We encourage neonatologists and ultrasonographers to take advantage of the impressive progress in CUS imaging quality in order to improve disease description and classification in the routine clinical practice. In the near future, an accurate classification of the lesions combined with the knowledge deriving from the clinical application of modern ultrasound techniques (e.g. functional CUS through ultrafast Doppler) may lead to more precise prediction of outcome and open new horizons in the understanding of pathophysiology of brain injury and complications related to GMH-IVH.

\section{ACKNOWLEDGEMENTS}

The members of eurUS.brain have read and approved this issue. Funding for this publication was provided by the European Society for Paediatric Research (ESPR).

\section{ADDITIONAL INFORMATION}

The online version of this article (https://doi.org/10.1038/s41390-020-0780-2) contains supplementary material, which is available to authorized users.

Competing interests A.P. has received consulting fees from Shire HGT, Inc. The authors declare no competing interests.
Publisher's note Springer Nature remains neutral with regard to jurisdictional claims in published maps and institutional affiliations.

\section{REFERENCES}

1. Volpe, J. J. Neurology of the Newborn 5th edn, 517-588 (Saunders Elsevier, Philadelphia, PA, 2008).

2. EXPRESS Group et al. One-year survival of extremely preterm infants after active perinatal care in Sweden. JAMA 301, 2225-2233 (2009).

3. Ancel, P. Y. \& Goffinet, F., the EPIPAGE-2 Writing Group. Epipage survival and morbidity of preterm children born at 22 through 34 weeks' gestation in France in 2011 results of the EPIPAGE-2 Cohort Study. JAMA Pediatr. 169, 230-238 (2015).

4. Stoll, B. J. et al. Eunice Kennedy Shriver National Institute of Child Health and Human Development Neonatal Research Network. Neonatal outcomes of extremely preterm infants from the NICHD Neonatal Research Network. Pediatrics 126, 443-456 (2010).

5. Ramenghi, L. A. et al. Cerebral venous thrombosis, intraventricular hemorrhage and white matter lesions in a preterm newborn with factor $\mathrm{V}$ (Leiden) mutation. Neuropediatrics 33, 97-99 (2002).

6. Kersbergen, K. J. et al. The spectrum of associated brain lesions in cerebral sinovenous thrombosis: relation to gestational age and outcome. Arch. Dis. Child Fetal Neonatal. Ed. 96, F404-F409 (2011).

7. Tajdar, M. et al. Heterozygous FGA p.Asp473Ter (fibrinogen Nieuwegein) presenting as antepartum cerebral thrombosis. Thromb. Res. pii: S0049-3848(17) 30536-4 (2017).

8. Kinoshita, Y., Okudera, T., Tsuru, E. \& Yokota, A. Volumetric analysis of the germinal matrix and lateral ventricles performed using MR images of postmortem fetuses. Am. J. Neuroradiol. 22, 382-388 (2001). 
9. Del Bigio, M. R. Cell proliferation in human ganglionic eminence and suppression after prematurity-associated hemorrhage. Brain 134, 1344-1361 (2011).

10. Scott, J. A. et al. Growth trajectories of the human fetal brain tissues estimated from 3D reconstructed in utero MRI. Int. J. Dev. Neurosci. 29, 529-536 (2011).

11. Ghazi-Birry, H. S. et al. Human germinal matrix: venous origin of hemorrhage and vascular characteristics. Am. J. Neuroradiol. 18, 219-229 (1997).

12. Nakamura, Y., Okudera, T., Fukuda, S. \& Hashimoto, T. Germinal matrix hemorrhage of venous origin in preterm neonates. Hum. Pathol. 21, 1059-1062 (1990).

13. Anstrom, J. A. et al. Subependymal veins in premature neonates: implications for hemorrhage. Pediatr. Neurol. 30, 46-53 (2004).

14. Meek, J. H., Tyszczuk, L., Elwell, C. E. \& Wyatt, J. S. Low cerebral blood flow is a risk factor for severe intraventricular hemorrhage. Arch. Dis. Child Fetal Neonatal. Ed. 81, F15-F18 (1999).

15. Miletin, J. \& Dempsey, E. M. Low superior vena cava flow on day 1 and adverse outcome in the very low birthweight infant. Arch. Dis. Child Fetal Neonatal. Ed. 93, F368-F371 (2008).

16. Greisen, G. Autoregulation of cerebral blood flow in newborn babies. Early Hum. Dev. 81, 423-428 (2005).

17. Harteman, J. C. et al. Atypical timing and presentation of periventricular hemorrhagic infarction in preterm infants: the role of thrombophilia. Dev. Med. Child Neurol. 54, 140-147 (2012).

18. Ramenghi, L. A. et al. Germinal matrix hemorrhage-intraventricular hemorrhage in very-low-birth-weight infants: the independent role of inherited thrombophilia. Stroke 42, 1889-1893 (2011).

19. Tortora, D. et al. Differences in subependymal vein anatomy may predispose preterm infants to GMH-IVH. Arch. Dis. Child Fetal Neonatal Ed. 103, F59-F65 (2018).

20. Tortora, D. et al. Variability of cerebral deep venous system in preterm and term neonates evaluated on MR SWI venography. Am. J. Neuroradiol. 37, 2144-2149 (2016).

21. Ballabh, P. Pathogenesis and Prevention of Intraventricular hemorrhage. Clin. Perinatol. 41, 47-67 (2014).

22. Wapner, R. J. Antenatal corticosteroids for periviable birth. Semin. Perinatol. 37, 410-413 (2013).

23. $\mathrm{Xu}, \mathrm{H}$. et al. Maturational changes in laminin, fibronectin, collagen IV, and perlecan in germinal matrix, cortex, and white matter and effect of betamethasone. J. Neurosci. Res. 86, 1482-1500 (2008).

24. Vinukonda, G. et al. Effect of prenatal glucocorticoids on cerebral vasculature of the developing brain. Stroke 41, 1766-1773 (2010).

25. Ment, L. R. et al. Prevention of intraventricular hemorrhage by indomethacin in male preterm infants. J. Pediatr. 145, 832-834 (2004).

26. Fowlie, P. W., Davis, P. G. \& McGuire, W. Prophylactic intravenous indomethacin for preventing mortality and morbidity in preterm infants. Cochrane Database Syst. Rev. CD000174 (2010).

27. Tarnow-Mordi, W. et al. Delayed versus immediate cord clamping in preterm infants. N. Engl. J. Med. 377, 2445-2455 (2017).

28. Rabe, H., Diaz-Rossello, J. L., Duley, L. \& Dowswell, T. Effect of timing of umbilical cord clamping and other strategies to influence placental transfusion at preterm birth on maternal and infant outcomes. Cochrane Database Syst. Rev. 8, CD003248 (2012).

29. Dolfin, T., Skidmore, M. B., Fong, K. W., Hoskins, E. M. \& Shennan, A. T. Incidence, severity, and timing of subependymal and intraventricular hemorrhages in preterm infants born in a perinatal unit as detected by serial real-time ultrasound. Pediatrics 71, 541-546 (1983).

30. Leviton, A. et al. The epidemiology of germinal matrix hemorrhage during the first half-day of life. Dev. Med. Child Neurol. 33, 138-145 (1991).

31. Perlman, J. M. \& Volpe, J. J. Intraventricular hemorrhage in extremely small premature infants. Am. J. Dis. Child. 140, 1122-1124 (1986).

32. Shaver, D. C. et al. Early and late intraventricular hemorrhage: the role of obstetric factors. Obstet. Gynecol. 80, 831-837 (1992).

33. Rhine, W. \& Blankenberg, F. G. Cranial ultrasonography. NeoReviews 2, 3-11 (2001).

34. Ballabh, P. et al. Angiogenic inhibition reduces germinal matrix hemorrhage. Nat. Med. 13, 477-485 (2007).

35. Ozduman, K. et al. Fetal stroke. Pediatr. Neurol. 30, 151-162 (2004).

36. Ramenghi, L. A. et al. Thrombophilia and fetal germinal matrix-intraventricular hemorrhage: does it matter? Ultrasound Obstet. Gynecol. 26, 574-576 (2005).

37. Sanapo, L. et al. Fetal intracranial hemorrhage: role of fetal MRI. Prenat. Diagn. 37, 827-836 (2017).

38. Brouwer, A. et al. Neurodevelopmental outcome of preterm infants with severe intraventricular hemorrhage and therapy for post-hemorrhagic ventricular dilatation. J. Pediatr. 152, 648-654 (2008).

39. Adams-Chapman, I. et al. Neurodevelopmental outcome of extremely low birth weight infants with posthemorrhagic hydrocephalus requiring shunt insertion. Pediatrics 121, e1167-e1177 (2008).

40. Klebermass-Schrehof, K. et al. Impact of low-grade intraventricular hemorrhage on long-term neurodevelopmental outcome in preterm infants. Childs Nerv. Syst. 28, 2085-2092 (2012).
41. Patra, K., Wilson-Costello, D., Taylor, H. G., Mercuri-Minich, N. \& Hack, M. Grades I-II intraventricular hemorrhage in extremely low birth weight infants: effects on neurodevelopment. J. Pediatr. 149, 169-173 (2006).

42. Tortora, D. et al. The effects of mild germinal matrix-intraventricular hemorrhage on the developmental white matter microstructure of preterm neonates: a DTI study. Eur. Radiol. 11, 2144-2149 (2017).

43. Gressens, P., Richelme, C., Kadhim, H. J., Gadisseux, J. F. \& Evrard, P. The germinative zone produces the most cortical astrocytes after neuronal migration in the developing mammalian brain. Biol. Neonate 62, 4-24 (1992).

44. Vasileiadis, G. T. et al. Uncomplicated intraventricular hemorrhage is followed by reduced cortical volume at near term age. Pediatrics 114, e367-e372 (2004).

45. Gram, M. et al. Hemoglobin induces inflammation after preterm intraventricular hemorrhage by methemoglobin formation. J. Neuroinflamm. 10, 100 (2013).

46. Supramaniam, V. et al. Microglia activation in the extremely preterm human brain. Pediatr. Res. 73, 301-309 (2013).

47. Chen, Z. et al. Role of iron in brain injury after intraventricular hemorrhage. Stroke 42, 465-470 (2011).

48. Ley, D. et al. High presence of extracellular hemoglobin in the periventricular white matter following preterm intraventricular hemorrhage. Front. Physiol. 7, 330 (2016).

49. Golden, J. A., Gilles, F. H., Rudelli, R. \& Leviton, A. Frequency of neuropathological abnormalities in very low birth weight infants. J. Neuropathol. Exp. Neurol. 56 472-478 (1997).

50. Larroque, B. et al. White matter damage and intraventricular hemorrhage in very preterm infants: the EPIPAGE study. J. Pediatr. 143, 477-483 (2003).

51. Guzzetta, F., Shackelford, G. D., Volpe, S., Perlman, J. M. \& Volpe, J. J. Periventricular intraparenchymal echodensities in the premature newborn: critical determinant of neurologic outcome. Pediatrics 78, 995-1006 (1986).

52. Volpe, J. J. Brain injury in the premature infant: overview of clinical aspects, neuropathology, and pathogenesis. Semin. Pediatr. Neurol. 5, 135-151 (1998).

53. Maitre, N. L. et al. Neurodevelopmental outcome of infants with unilateral or bilateral periventricular hemorrhagic infarction. Pediatrics 124, e1153-e1160 (2009).

54. Bassan, $\mathrm{H}$. et al. Ultrasonographic features and severity scoring of periventricular hemorrhagic infarction in relation to risk factors and outcome. Pediatrics 117, 2111-2118 (2006)

55. Dudink, J. et al. Venous subtypes of preterm periventricular hemorrhagic infarction. Arch. Dis. Child Fetal Neonatal. Ed. 93, F201-F206 (2008).

56. Bassan, $\mathrm{H}$. et al. Neurodevelopmental outcome in survivors of periventricular hemorrhagic infarction. Pediatrics 120, 785-792 (2007).

57. Davis, A. S. et al. Outcomes of extremely preterm infants following severe intracranial hemorrhage. J. Perinatol. 34, 203-208 (2014).

58. Sheehan, J. W. et al. Severe intraventricular hemorrhage and withdrawal of support in preterm infants. J. Perinatol. 37, 441-447 (2017).

59. Murphy, B. P. et al. Posthemorrhagic ventricular dilatation in the premature infant: natural history and predictors of outcome. Arch. Dis. Child Fetal Neonatal. Ed. 87, F37-F41 (2002).

60. Brouwer, A. J., Groenendaal, F., Han, K. S. \& de Vries, L. S. Treatment of neonatal progressive ventricular dilatation: a single-centre experience. J. Matern. Fetal Neonatal. Med. 28(Suppl 1), 2273-2279 (2015).

61. Brouwer, A. J., Groenendaal, F., Benders, M. J. \& de Vries, L. S. Early and late complications of germinal matrix-intraventricular hemorrhage in the preterm infant: what is new? Neonatology 106, 296-303 (2014).

62. Robinson, S. Neonatal posthemorrhagic hydrocephalus from prematurity: pathophysiology and current treatment concepts. J. Neurosurg. Pediatr. 9, 242-258 (2012).

63. Brouwer, A. J. et al. Cognitive and neurological outcome at the age of 5-8 years of preterm infants with post-hemorrhagic ventricular dilatation requiring neurosurgical intervention. Neonatology 101, 210-216 (2012).

64. Leijser, L. M. et al. Posthemorrhagic ventricular dilatation in preterm infants: When best to intervene? Neurology 90, e698-e706 (2018).

65. Ramenghi, L. A., Mosca, F., Counsell, S. \& Rutherford, M. A. in Pediatric Neuroradiology 1st edn, Vol. 1 (Brain) (ed. Tortori-Donati, P.) 199-234 (Springer, Berlin, Germany, 2005)

66. Sannia, A. et al. Different gestational ages and changing vulnerability of the premature brain. J. Matern. Fetal Neonatal Med. 28(Suppl. 1), 2268-2272 (2015).

67. Van Wezel-Meijler, G. Neonatal Cranial Ultrasonography 1st edn., 53 (Springer, Berlin, 2007).

68. Papile, L. A., Burstein, J., Burstein, R. \& Koffler, H. Incidence and evolution of subependymal and intraventricular hemorrhage: a study of infants with birth weights less than 1,500 gm. J. Pediatr. 92, 529-534 (1978).

69. Bowerman, R. A., Donn, S. M., Silver, T. M. \& Jaffe, M. H. Natural history of neonatal periventricular/intraventricular hemorrhage and its complications: sonographic observations. Am. J. Roentgenol. 143, 1041-1052 (1984).

70. Kuban, K. \& Teele, R. L. Rationale for grading intracranial hemorrhage in premature infants. Pediatrics 74, 358-363 (1984). 
71. Horbar, J. D. et al. Mortality and neonatal morbidity among infants 501 to 1500 grams from 2000 to 2009. Pediatrics 129, 1019-1026 (2012).

72. Paneth, N. Brain Damage in the Preterm Infant 71-98 (MacKeith Press, London, 1994).

73. Hope, P. L. et al. Precision of ultrasound diagnosis of pathologically verified lesions in the brains of very preterm infants. Dev. Med. Child Neurol. 30, 457-471 (1988).

74. Shackelford, G. D. \& Volpe, J. J. Cranial ultrasonography in the evaluation of neonatal intracranial hemorrhage and its complications. J. Perinat. Med. 13, 293-304 (1985).

75. Govaert, P. \& De Vries, L. S. An Atlas of Neonatal Brain Sonography 2nd edn, 199-224 (Mac Keith Press, London, 2010).

76. Raets, M. M., Dudink, J. \& Govaert, P. Neonatal disorders of germinal matrix. J. Matern. Fetal Neonatal. Med. 28(Suppl. 1), 2286-2290 (2015).

77. Horsch, S., Kutz, P. \& Roll, C. Late germinal matrix hemorrhage-like lesions in very preterm infants. J. Child Neurol. 25, 809-814 (2010).

78. Hambleton, G. \& Wigglesworth, J. S. Origin of intraventricular hemorrhage in the preterm infant. Arch. Dis. Child. 51, 651-659 (1976).

79. Parodi, A. et al. Low-grade intraventricular hemorrhage: is ultrasound good enough? J. Matern. Fetal Neonatal Med. 28(Suppl. 1), 2261-2264 (2015).

80. Rypens, E. et al. Hyperechoic thickened ependyma: sonographic demonstration and significance in neonates. Pediatr. Radiol. 24, 550-553 (1994).

81. Dewbury, K. C. \& Bates, R. I. Neonatal intracranial hemorrhage: the cause of the ultrasound appearances. Br. J. Radiol. 56, 783-789 (1983).

82. Koumanidou, $C$. et al. Hemorrhage in the cavum septi pellucidi, and a brief review of the literature. Neuroradiology 44, 770-774 (2002).

83. Armstrong, D. L., Sauls, C. D. \& Goddard-Finegold, J. Neuropathologic findings in short-term survivors of intraventricular hemorrhage. Am. J. Dis. Child. 141, 617-621 (1987).

84. Perlman, J. M., Rollins, N., Burns, D. \& Risser, R. Relationship between periventricular intraparenchymal echodensities and germinal matrix-intraventricular hemorrhage in the very low birth weight neonate. Pediatrics 91, 474-480 (1993).

85. Taylor, G. A. Effect of germinal matrix hemorrhage on terminal vein position and patency. Pediatr. Radio. 25(Suppl. 1), S37-S40 (1995).

86. Takashima, S., Mito, T. \& Ando, Y. Pathogenesis of periventricular white matter hemorrhages in preterm infants. Brain Dev. 8, 25-30 (1986).

87. Ghazi-Birry, H. S. et al. Human germinal matrix: venous origin of hemorrhage and vascular characteristics. Am. J. Neuroradiol. 18, 219-229 (1997).

88. Toft, P. B., Leth, H., Peitersen, B. \& Lou, H. C. Metabolic changes in the striatum after germinal matrix hemorrhage in the preterm infant. Pediatr. Res. 41, 309-316 (1997).

89. Fleischer, A. C. et al. Serial sonography of posthemorrhagic ventricular dilatation and porencephaly after intracranial hemorrhage in the preterm neonate. Am. J. Neuroradiol. 4, 971-975 (1983). AJR 1983;141:451-455.

90. Grant, E. G. et al. Evolution of porencephalic cysts from intraparenchymal hemorrhage in neonates. Sonographic evidence. Am. J. Neuroradiol. 3, 47-50 (1982). AiR 1982; 138:467-470.

91. Donn, S. M. \& Bowerman, R. A. Neonatal posthemorrhagic porencephaly. Ultrasonographic features. Am. J. Dis. Child 36, 707-709 (1982).

92. Pierrat, V. et al. Ultrasound diagnosis and neurodevelopmental outcome of localised and extensive cystic periventricular leukomalacia. Arch. Dis. Child Fetal Neonatal. Ed. 84, F151-F156 (2001).
93. Roze, E. et al. Neonatal DTl early after birth predicts motor outcome in preterm infants with periventricular hemorrhagic infarction. Pediatr. Res. 78, 298-303 (2015).

94. De Vries, L. S., Groenendaal, F., Gooskens, R. \& Hanlo, P. Unilateral posthemorrhagic hydrocephalus in the neonatal period or later in infancy. Acta Paediatr. 89, 77-81 (2000).

95. Whitelaw, A. Intraventricular hemorrhage and posthemorrhagic hydrocephalus: pathogenesis, prevention and future interventions. Semin. Neonatol. 6, 135-146 (2001).

96. Rademaker, K. J. et al. Rapidly progressive enlargement of the fourth ventricle in the preterm infant with post-hemorrhagic ventricular dilatation. Acta Paediatr. 84, 1193-1196 (1995).

97. Levene, M. I. \& Starte, D. R. A longitudinal study of post-hemorrhagic ventricular dilatation in the newborn. Arch. Dis. Child. 56, 905-910 (1981).

98. Levene, M. I. Measurement of the growth of the lateral ventricles in preterm infants with real-time ultrasound. Arch. Dis. Child. 56, 900-904 (1981).

99. Davies, M. W., Swaminathan, M., Chuang, S. L. \& Betheras, F. R. Reference ranges for the linear dimensions of the intracranial ventricles in preterm neonates. Arch. Dis. Child Fetal Neonatal. Ed. 82, F218-F223 (2000).

100. Brouwer, M. J. et al. New reference values for the neonatal cerebral ventricles. Radiology 262, 224-233 (2012).

101. Brann, B. S. 4th, Qualls, C., Wells, L. \& Papile, L. Asymmetric growth of the lateral cerebral ventricle in infants with posthemorrhagic ventricular dilation. J. Pediatr. 118, 108-112 (1991).

102. Brouwer, A. J. et al. European perspective on the diagnosis and treatment of posthemorrhagic ventricular dilatation. Arch. Dis. Child Fetal Neonatal. Ed. 97, F50-F55 (2012).

103. Raets, M. et al. Brain vein disorders in newborn infants. Dev. Med. Child Neurol. 57, 229-240 (2015).

104. Ecury-Goossen, G. M., Camfferman, F. A., Leijser, L. M., Govaert, P. \& Dudink J. State of the art cranial ultrasound imaging in neonates. J. Vis. Exp. 2, e52238 (2015).

105. Wang, J., Wang, J., Sun, J. \& Gong, X. Evaluation of the anatomy and variants of internal cerebral veins with phase-sensitive MR imaging. Surg. Radiol. Anat. 32, 669-674 (2010).

106. Demené, C., Mairesse, J., Baranger, J., Tanter, M. \& Baud, O. Ultrafast Doppler for neonatal brain imaging. Neuroimage 185, 851-856 (2019).

Open Access This article is licensed under a Creative Commons Attribution 4.0 International License, which permits use, sharing, adaptation, distribution and reproduction in any medium or format, as long as you give appropriate credit to the original author(s) and the source, provide a link to the Creative Commons license, and indicate if changes were made. The images or other third party material in this article are included in the article's Creative Commons license, unless indicated otherwise in a credit line to the material. If material is not included in the article's Creative Commons license and your intended use is not permitted by statutory regulation or exceeds the permitted use, you will need to obtain permission directly from the copyright holder. To view a copy of this license, visit http://creativecommons. org/licenses/by/4.0/.

(c) The Author(s) 2020

\section{eurUS.brain group}

Thais Agut ${ }^{7}$, Ana Alarcon ${ }^{7}$, Roberta Arena ${ }^{8}$, Marco Bartocci ${ }^{9}$, Mayka Bravo ${ }^{6}$, Fernando Cabañas ${ }^{10}$, Nuria Carreras ${ }^{7}$, Olivier Claris ${ }^{11}$, Jeroen Dudink $^{12}$, Monica Fumagalli ${ }^{13,14}$, Paul Govaert ${ }^{2,3,4}$, Sandra Horsch ${ }^{5,15}$, Alessandro Parodi ${ }^{1}$, Adelina Pellicer ${ }^{6}$, Luca A. Ramenghi ${ }^{1}$, Charles C. Roehr ${ }^{16}$, Sylke Steggerda ${ }^{17}$ and Eva Valverde ${ }^{6}$

\footnotetext{
${ }^{7}$ Department of Neonatology, Institut de Recerca Pediàtrica, Hospital Sant Joan de Déu, Barcelona, Spain. ${ }^{8}$ Catholic University of the Sacred Heart, A. Gemelli Hospital, Rome, Italy. ${ }^{9}$ Department of Women's and Children's Health, Karolinska University Hospital, Karolinska Insitute, Stockholm, Sweden. ${ }^{10}$ Department of Neonatology, Quironsalud Madrid University Hospital and Biomedical Research Foundation, La Paz University Hospital Madrid, Madrid, Spain. ${ }^{11}$ Service de néonatologie et de réanimation néonatale, Hospices Civils de Lyon, Université Claude Bernard Lyon, Villeurbanne, France. ${ }^{12}$ UMCU-Wilhelmina Children's Hospital, Lundlaan 6, 3584 EA Utrecht, The Netherlands. ${ }^{13}$ Department of Clinical Sciences and Community Health, University of Milan, Milan, Italy. ${ }^{14}$ Fondazione IRCCS Ca' Granda Ospedale Maggiore Policlinico NICU, Milan, Italy. ${ }^{15}$ Department Clinical Science Intervention and Technology (CLINTEC), Karolinska Institutet, Stockholm, Sweden. ${ }^{16}$ Department of Paediatrics, Medical Sciences Division, Newborn Services, University of Oxford, Oxford, United Kingdom. ${ }^{17}$ Department of Neonatology, Leiden University Medical Center, Leiden, The Netherlands.
} 